\title{
SUPERIOR MESENTERIC ARTERY SYNDROME - A REVIEW
}

Aneeta Datey ${ }^{1}$, Sanjay Datey ${ }^{2}$, Pramod Saki ${ }^{3}$, Vaibhav Ingle ${ }^{4}$, Ankur Kumbhkar ${ }^{5}$

\section{HOW TO CITE THIS ARTICLE:}

Aneeta Datey, Sanjay Datey, Pramod Saki, Vaibhav Ingle, Ankur Kumbhkar. "Superior Mesenteric Artery Syndrome - A Review". Journal of Evolution of Medical and Dental Sciences 2014; Vol. 3, Issue 06, February 10; Page: $1426-1433$, DOI: $10.14260 /$ jemds/2014/2002

ABSTRACT: Superior mesenteric artery (SMA) syndrome is a rare acquired disorder in which an acute angulation of SMA causes compression and obstruction of the third part of the duodenum between the SMA and the aorta. The diagnosis is usually made by exclusion. A large number of debilitating conditions leading to a loss of fatty tissue such as anorexia nervosa, malabsorption, or hyper catabolic states like burns, major surgery, severe injuries, or malignancies can cause this syndrome. To our knowledge there are no cases reported in the Indian literature, though many such cases are being diagnosed and successfully treated the world over. We recently diagnosed and successfully treated a patient of S.M.A. syndrome in Shri Aurobindo Institute of Medical Sciences, Medical College and Post-Graduate Institute. We take the opportunity to review the literature on S.M.A. syndrome.

KEYWORDS: Duodenal obstruction, SMA syndrome.

S.M.A.S. - A CASE REPORT: A 60 years old male farmer was admitted from medical O.P.D. with two weeks complaints of recurrent bilious vomiting, 2-3 hours after meals and abdominal distension. The patient was passing hard stools every second or third day. He reported significant loss of weight over last month. There were no other complaints. He was addicted to tobacco chewing and occasionally consumes alcohol.

Except for an emaciated and dehydrated look there was no abnormality on general and systemic examination. His hemoglobin was $13.3 \mathrm{gm} \%$ with normal hematological picture; blood urea $105 \mathrm{mg} \%$, serum creatinine $3.88 \mathrm{mg} \%$; serum proteins $4.46 \mathrm{gm} . \%$ with albumin $1.9 \mathrm{gm} . \%$, globulin $2.56 \mathrm{gm} \%$ (A/G ratio=0.7); serum bilirubin $0.93 \mathrm{mg} \%$, S.G.O.T. 48 units, S.G.P.T.46 units and I.N.R. was 1.1.

His barium study showed massive dilatation of the stomach which reached up to the pelvic brim as well as dilatation of 1 st, 2 nd and $3^{\text {rd }}$ parts of duodenum.

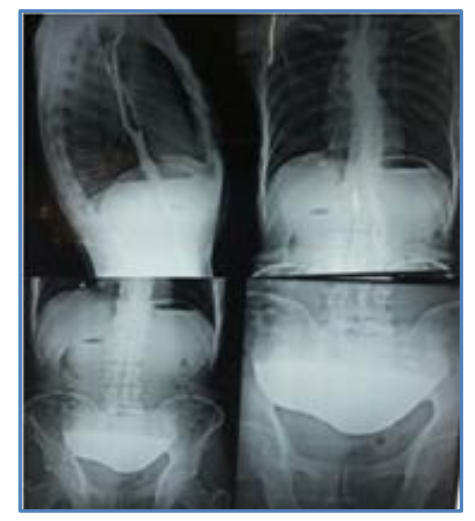

His abdominal sonography revealed dilated stomach and 1 st $-3^{\text {rdparts }}$ of duodenum with the superior mesenteric artery deviated to the left and the aorto-mesenteric distance of $12 \mathrm{~mm}$. 


\section{REVIEW ARTICLE}

Upper G.I endoscopy showed grade B esophagitis, small hiatus hernia and mucosal fold thickening and narrowed lumen of distal duodenum, but no intraluminal growth or stricture was seen.

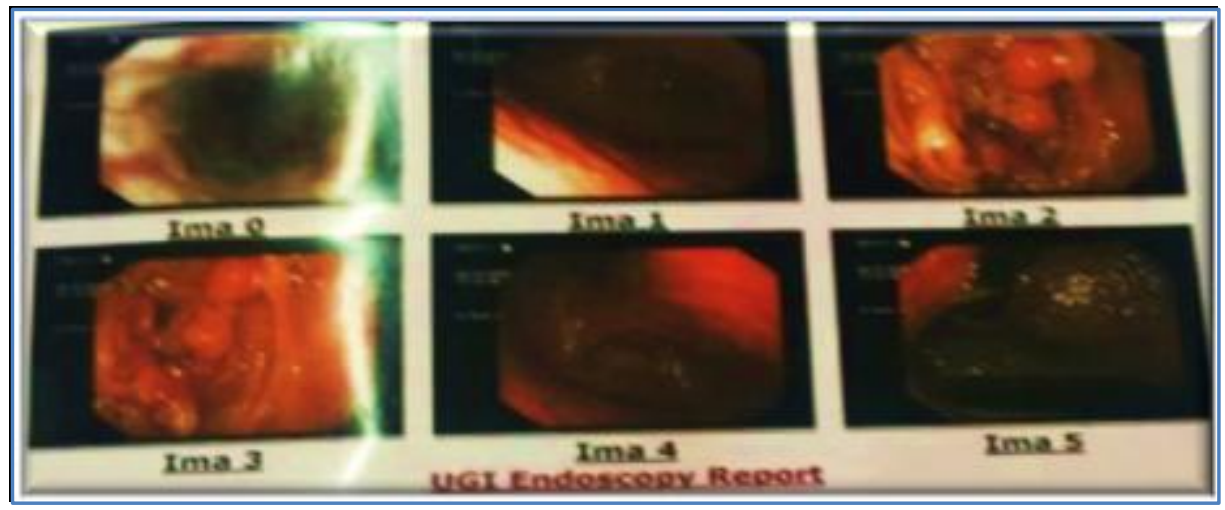

A contrast enhanced C.T. scan of the abdomen (rectal and oral iodinated contrast \& venous contrast) showed dilated $1^{\text {st }}-3^{\text {rd }}$ part of duodenum with aortic mesenteric angle of 23 degree and aorta -mesenteric artery distance of $12 \mathrm{~mm}$. A $1.6 \times 1.4 \mathrm{~cm}$ hemangioma in the posterosuperior segment of right lobe of liver was incidentally noted.
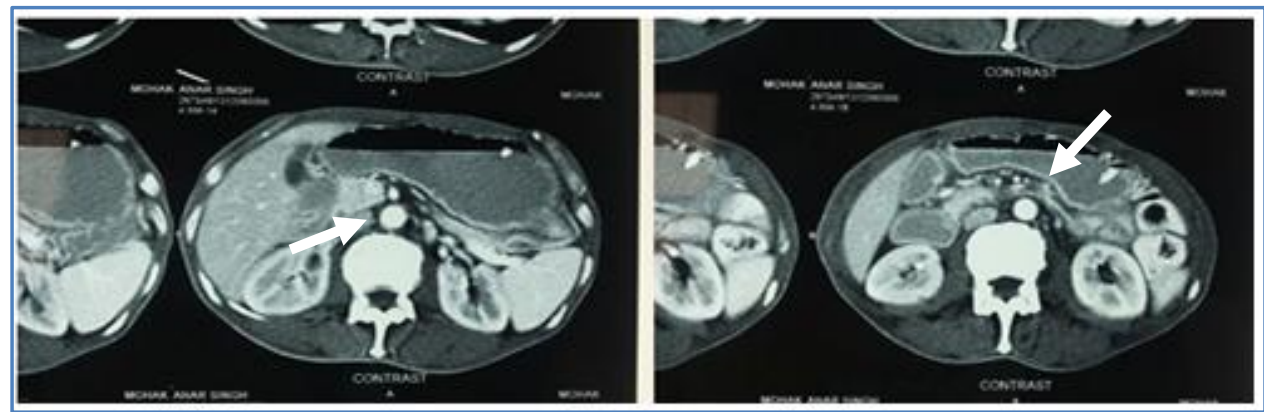

C.E.C.T. abdomen showing compression of $3^{\text {rd }}$ Part of duodenum between aorta and S.M.A.
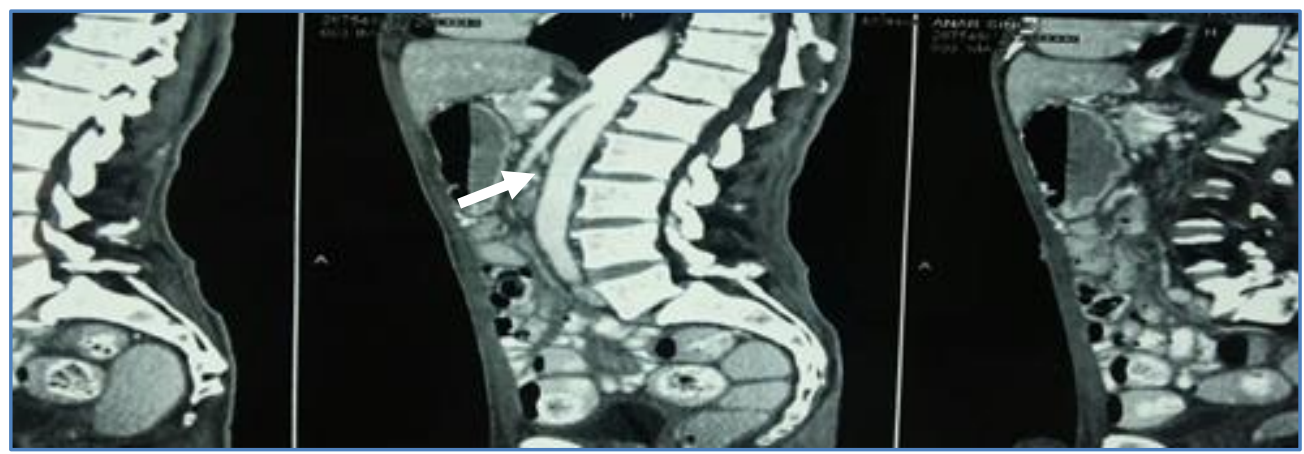

CECT abdomen showing the aorto-mesenteric angle. 
The patient improved with nasogastric suction and intravenous fluids; his blood urea came to $53 \mathrm{mg} \%$ and serum creatinine $1.8 \mathrm{mg} \%$. He however denied surgery and left against medical advice, only to return after 10 days with worsening of obstructive symptoms. After initial conservative treatment with nasogastric suction and intravenous alimentation he was subjected to surgery. The ligament of Treitz was cut, third part of duodenum was found to be compressed by the S.M.A., and side to side duodenojejunostomy was done between the $3^{\text {rd }}$ part of duodenum and jejunum at $30 \mathrm{~cm}$ from duodenojejunal junction.

Apost-operative Gastrograffin study showed a well-functioning anastomosis.

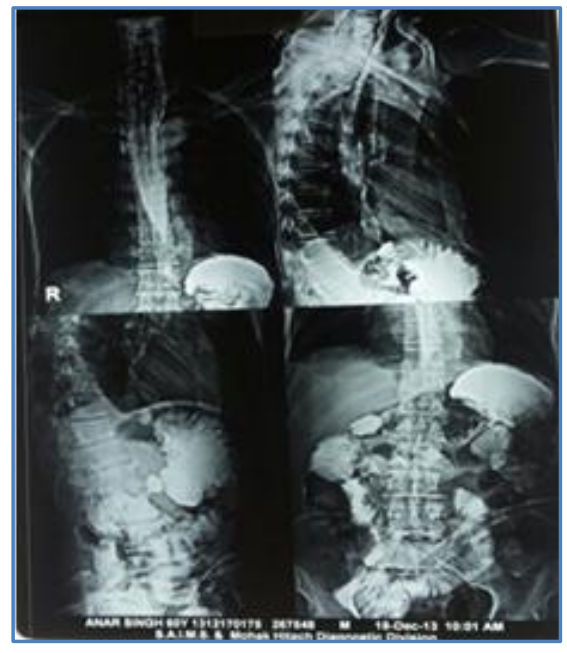

The patient's recovery was complicated by abdominal sepsis and hypoproteinemia but after three weeks the patient was discharged from the hospital with no symptoms of duodenal obstruction.

REVIEW OF LITERATURE: SMA syndrome (also known as Willkie's syndrome, gastro-vascular syndrome, cast syndrome (due to immobilization in a body cast), chronic duodenal ileus, intermittent arterio-mesenteric occlusion or AO syndrome) was first described by Von Rokitanski by autopsy in 1861. In 1908, Laffer ${ }^{1}$ presented one of the first review of the condition. Wilkie in $1927^{2}$ reported a detailed clinical and pathophysiologic study in a series of 64 patients and suggested treatment approaches.

Skepticism about the existence of the condition continued until the 1960s till new radiologic techniques provided adequate evidence to support the existence of SMAS. Some still question whether it is a true entity ${ }^{3}$ and others believe that the syndrome is over diagnosed ${ }^{4}$.In the recent years the reported incidence has been on the rise, possibly due to increased physician awareness. ${ }^{5}$

The defining feature of this entity is upper gastrointestinal obstruction caused by compression of the third part of the duodenum between the SMA anteriorly and the aorta posteriorly.

Origin and anatomical relations of superior mesenteric artery: SMA is a direct branch of abdominal aorta distal to the coeliac trunk and passes anterior to the third part of the duodenum before supplying branches to various parts of the gut. Normally, fat and lymphatic tissues around the SMA provide protection to the duodenum against compression by the artery. 


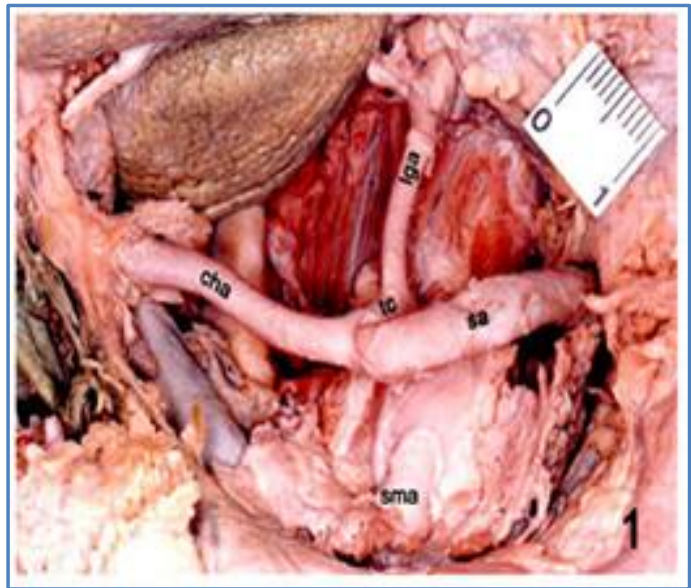

Fig. 1: Origin and anatomical relations of SMA

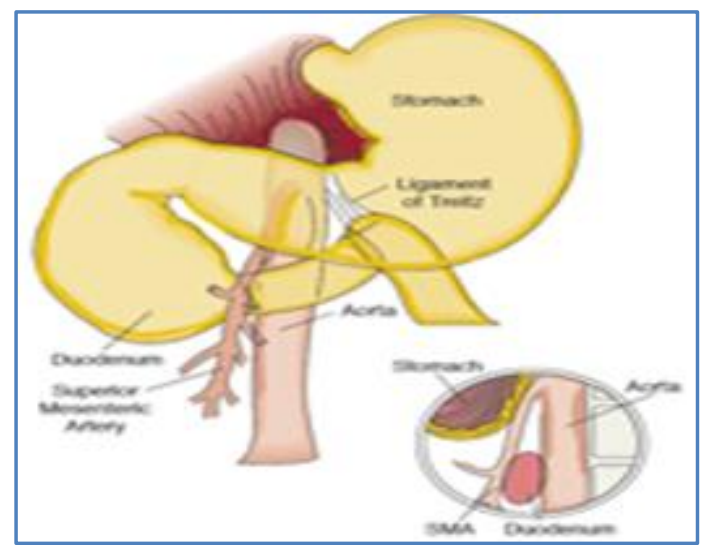

\section{Fig. 2: Lateral view in superior mesenteric artery syndrome shows compression of duodenum by superior mesenteric artery. Arrow indicates abnormal, narrowed aortomesenteric angle.}

Normally, the aortomesenteric angle and aortomesenteric distance is $25^{\circ}$ to $60^{\circ}$ and 10 to 28 $\mathrm{mm}$ respectively. In SMA syndrome, usually associated with conditions of severe weight loss, the fat cushion around the SMA is diminished, hereby increasing the acuteness of the aortomesenteric angle to $6^{\circ}$ to $15^{\circ}$ and reducing the distance between the two to 2 to $8 \mathrm{~mm} .^{6}$

Many causes for SMAS have been suggested. Conditions like increased spinal lordosis, application of a body cast, short ligament of Treitz, a high insertion of the duodenum at the ligament of Treitz, a congenital low origin of the superior mesenteric artery and compression of the duodenum caused by peritoneal adhesions as a result of duodenal mal-rotation may also precipitate this syndrome. Rarely, SMA syndrome has been reported after abdominal surgery.7-15

Clinical presentation: Patients usually have chronic insidious symptomatology but may present with an acute exacerbation of chronic symptoms. The symptoms are usually long-standing and vague, with early satiety and anorexia and recurrent episodes of abdominal pain, often associated with bilious vomiting. Less often there is an acute presentation characterized by signs and symptoms of 
duodenal obstruction and rarely "stabbing" postprandial abdominal pain due to both the duodenal compression and the compensatory reversed peristalsis. Weight loss is common because patients often regurgitate their food or become afraid to eat. ${ }^{16}$ Weight loss can in turn exacerbate the condition. ${ }^{16-18}$

Symptoms can be relieved by postural changes in the prone or knee -chest position, suggesting vascular compression. However relief with postural change is inconsistent, its absence does not rule out vascular compressive syndromes. ${ }^{16}$ Moreover, peptic ulcer disease coexists with SMAS in up to $25 \%$ of cases. ${ }^{19,} 20$

Whether duodenal obstruction precedes the peptic ulcer or the peptic disease contributes to the arteriomesenteric duodenal compression is uncertain.

Diagnosis: The diagnosis of SMA syndrome is based on clinical symptoms and radiologic evidence of duodenal obstruction.

Plain radiograph demonstrates a dilated, fluid- and gas-filled stomach. Barium radiography shows dilatation of the first and second part of the duodenum, extrinsic compression of the third part, and a collapsed small bowel distal to the crossing of the SMA.

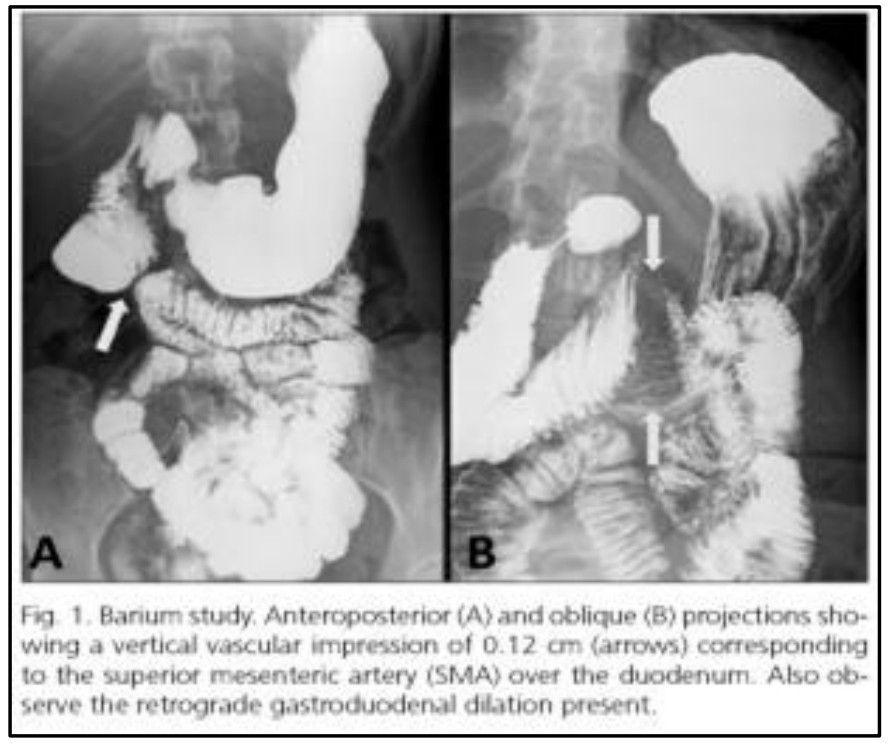

Contrast-enhanced CT scan or magnetic resonance angiography (MRA) enables visualization of vascular compression of the duodenum and precise measurement of aortomesenteric distance. Both these procedures are noninvasive and reportedly equivalent to conventional contrast angiography, which has previously been suggested as the reference standard for establishing the diagnosis. 21,22

Endoscopic examination may visualize a pulsatile extrinsic compression, suggestive of this condition. ${ }^{22}$

Treatment: Traditionally, treatment has consisted of conservative measures such as nasogastric decompression and hyper alimentation followed by oral feeding with frequent small meals. Posturing maneuvers lying in the left lateral decubitus position during meals and motility agents may be helpful 
in some patients. Medical treatment is usually successful in patients with a short history and a relatively minor degree of duodenal stasis shown radiologically. ${ }^{23}$

Surgery is to be considered if conservative treatment fails along with a long history of indigestion, progressive weight loss, pronounced dilatation and stasis of the duodenum. ${ }^{24}$, ${ }^{25}$ Duodenojejunostomy is effective in the majority of patients. ${ }^{4} \mathrm{~A}$ 7-year follow-up study of 16 patients treated with duodenojejunostomy found that outcome was regarded as excellent by 3 patients, good by 6 , satisfactory by 5 , and poor by 2 patients. ${ }^{26}$ Although effective, conventional surgery may not be suitable for debilitated patients. Laparoscopic minimally invasive duodenojejunostomy has been used since 1998.27, ${ }^{28}$ Laparoscopic lysis of the ligament of Treitz with mobilization of the duodenum is another minimally invasive approach.

Hutchinson and Bassett and Munns and colleagues both reported 100\% success rates without any surgical intervention. ${ }^{5}{ }^{29}$ However; both these series were in orthopedic patients who had an acute postoperative episode. Biopsy specimens of the duodenum and jejunum should be obtained before surgery to exclude infiltrative, infective, neurologic or malignant causes for the duodenal dilatation and chronic idiopathic intestinal pseudo-obstruction.17,30,31 Duodenojejunostomy from the second portion of the duodenum to the jejunum has been considered the surgical treatment of choice in many surgical publications. ${ }^{22,23,32,33}$

Other procedures include gastrojejunostomy, Roux-en-Y duodenojejunostomy and anterior transposition of the third part of the duodenum-the last technique being an effective and permanent direct approach. ${ }^{34}$ Lysis of the ligament of Treitz is specially recommended in children as it does not include any intestinal anastomosis. ${ }^{16,35}$ and 36

CONCLUSION: With the advent of newer imaging techniques Superior mesenteric artery syndrome has been clearly defined. As it is frequently associated with a wide range of predisposing conditions, clinicians must consider this syndrome in such a setting. More number of patients is likely to be diagnosed in future with better awareness of the disease. Conventional surgical procedures have resulted in good results but may be associated with operative risk in very debilitated patients. Minimally invasive laparoscopic surgical treatment may replace the conventional operative procedures in future.

\section{REFERENCES:}

1. Laffer LC. Acute dilatation of the stomach and acute arteriomesenteric ileus. Ann Surg 1908; 47: 94-7.

2. Wilkie DP. Chronic duodenal ileus. Am J Med Sci 1927; 173: 643-9.

3. Cimino CV. Arteriomesenteric occlusion of the duodenum: an entity? Radiology 1961; 76: 828-9.

4. Hines JR, Gore RM, Ballantyne GH. Superior mesenteric artery syndrome -- diagnostic criteria and therapeutic approaches. Am J Surg 1984; 148: 630-2.

5. Hutchinson DT, Bassett GS. Superior mesenteric artery syndrome in pediatric orthopedic patients. ClinOrthop 1990; 250: 250-7.

6. Lippl F, Hannig C, Weiss W, Allescher HD, Classen M, Kurjak M. Superior mesenteric artery syndrome: diagnosis and treatment from the gastroenterologist's view. J Gastroenterol. 2002;37:640-3. 
7. Cohen LB, Field SP, Sachar DB. The superior mesenteric artery syndrome: the disease that isn't, or is it? J ClinGastroenterol 1985; 7: 113-6.

8. Strong EK. Mechanics of arteriomesenteric duodenal obstruction and direct surgical attack upon etiology. Ann Surg 1958; 148: 725-30.

9. Elbadawy MH. Chronic superior mesenteric artery syndrome in anorexia nervosa. $\mathrm{Br} \mathrm{J}$ Psychiatry 1992; 160: 552-4.

10. McClenathan JH. Hyperthyroidism as a cause of superior mesenteric artery syndrome. Am J Dis Child 1988; 142: 685-6.

11. Milner EA, Cioffi WG, McManus WF, Pruitt BA Jr. Superior mesenteric artery syndrome in a burn patient. Nutr Clin Pract 1993; 8: 264-6.

12. Philip PA. Superior mesenteric artery syndrome in a child with brain injury. Case report. Am J Phys Med Rehabil 1981; 70: 280-2.

13. Ramos M. Recurrent superior mesenteric artery syndrome in a quadriplegic patient. Arch Phys Med Rehabil 1975; 56: 86-8.

14. Roth EJ, Fenton LL, Gaebler-Spira DJ, Frost FS, Yarkony GM. Superior mesenteric artery syndrome in acute traumatic quadriplegia: case reports and literature review. Arch Phys Med Rehabil 1991; 72: 417-20.

15. Vannatta JB, Cagas CR, Cramer RI. Superior mesenteric artery (Wilkie's) syndrome: report of three cases and review of the literature. South Med J 1976; 69: 1461-5.

16. Akin JT, Gray SW, Skandalakis JE. Vascular compression of the duodenum: presentation of 10 cases and review of the literature. Surgery 1976; 79: 515-22.

17. Anderson JR, Earnshaw PM, Fraser GM. Extrinsic compression of the third part of the duodenum. Clin Radiol 1982; 33: 75-81.

18. Marchant EA, Alvear DT, Fagelman KM. True clinical entity of vascular compression of the duodenum in adolescence. Surg Gynecol Obstet 1989; 168: 381-6.

19. Anderson WC, Vivit R, Kirsh IE. Arteriomesenteric duodenal compression syndrome. Its association with peptic ulcer. Am J Surg 1973; 125: 681-9.

20. Pentlow BD, Dent RG. Acute vascular compression of the duodenum in anorexia nervosa. Br J Surg 1981; 68: 665-6.

21. Bedoya R, Lagman SM, Pennington GP, Kirdnual A. Clinical and radiological aspects of the superior mesenteric artery syndrome. J Fla Med Assoc. 1986;73:686-9.

22. Gustafsson L, Falk A, Lukes PJ, Gamklou R. Diagnosis and treatment of superior mesenteric artery syndrome. Br J Surg. 1984;71:499-501.

23. Jones SA, Carter R, Smith LL. Arteriomesenteric duodenal compression. Am J Surg 1960; 100: 262-77.

24. Goin LS, Wilk SP. Intermittent arteriomesenteric occlusion of the duodenum. Radiology 1956; 67: 729-37.

25. Appel MF, Bentliff PS, Dickson JH. Arteriomesenteric duodenal compression syndrome: comparison of methods of treatment. South Med J 1976; 69: 340-2.

26. Ylinen P, Kinnunen J, Hockerstedt K. Superior mesenteric artery syndrome. A follow-up study of 16 operated patients. J ClinGastroenterol. 1989;11:386-91.

27. Gersin KS, Heniford BT. Laparoscopic duodenojejunostomy for treatment of superior mesenteric artery syndrome. Jsls. 1998;2:281-4. 
28. Richardson WS, Surowiec WJ. Laparoscopic repair of superior mesenteric artery syndrome. Am J Surg. 2001;181:377-8.

29. Munns SW, Morrissy RT, Golladay ES, McKenzie CN. Hyperalimentation for superior mesenteric artery (cast) syndrome following correction of spinal deformity. J Bone Joint Surg [Am] 1984; 66: 1175-7.

30. Applegate GR, Cohen AJ. Dynamic CT in superior mesenteric artery syndrome. J Comput Assist Tomogr 1988; 12: 976-80.

31. Lee MG, Terry SI: Arteriomesenteric duodenal occlusion associated with strongyloidiasis. J Trop Med Hyg 1989; 92: 41-5.

32. Barner HB, Sherman CD Jr. Vascular compression of the duodenum. IntAbstrSurg 1963; 117: 103-18.

33. Lundell L, Thulin A: Wilkie's syndrome -- a rarity? Br J Surg 1980; 67: 604-6.

34. Duvie SO. Anterior transposition of the third part of the duodenum in the management of chronic duodenal compression by the superior mesenteric artery. IntSurg 1988; 73: 140-3.

35. Wayne ER, Burrington JD. Duodenal obstruction by the superior mesenteric artery in children. Surgery 1978; 72: 762-8.

36. Welsch T, Büchler MW, Kienle P.Recalling superior mesenteric artery syndrome. Dig Surg. 2007;24(3):149-56. Epub 2007 Apr 27.

\section{AUTHORS:}

1. Aneeta Datey

2. Sanjay Datey

3. Pramod Saki

4. Vaibhav Ingle

5. Ankur Kumbhkar

\section{PARTICULARS OF CONTRIBUTORS:}

1. Professor, Department of Medicine, Shri Aurobindo Institute of Medical Sciences, Medical College and Post-Graduate Institute.

2. Professor, Department of Surgery, Shri Aurobindo Institute of Medical Sciences, Medical College and Post-Graduate Institute.

3. Associate Professor, Department of Radiodiagnosis, Shri Aurobindo Institute of Medical Sciences, Medical College and PostGraduate Institute.
4. Assistant Professor, Department of Medicine, Shri Aurobindo Institute of Medical Sciences, Medical College and Post-Graduate Institute.

5. Senior Resident, Department of Medicine, Shri Aurobindo Institute of Medical Sciences, Medical College and Post-Graduate Institute.

\section{NAME ADDRESS EMAIL ID OF THE CORRESPONDING AUTHOR:}

Dr. Aneeta Datey,

Manushri-43,

Chikitsak Nagar, Opp. Bombay Hospital, Indore, M.P., India, 452010.

E-mail: aneetadatey@hotmail.com

Date of Submission: 17/01/2014.

Date of Peer Review: 18/01/2014.

Date of Acceptance: 28/01/2014.

Date of Publishing: 05/02/2014. 